\title{
Self-control, Sense of Responsibility, and Respect for Others of Performing Artists in a Higher Education Institution
}

\author{
Raymond L. Patterson \\ Department of Physical Education, School of Education, Holy Angel University, Philippines
}

Copyright $\mathrm{C} 2019$ by authors, all rights reserved. Authors agree that this article remains permanently open access under the terms of the Creative Commons Attribution License 4.0 International License

\begin{abstract}
Student performers who would like to be part of the performing arts group already possess the skills required for them to be part of the group. Skills, however, are not enough to become a good performer. Rather, these should be complemented by a positive attitude. Self-control, sense of responsibility and respect for others are the predictors of performing skills of a performing artists and predictor of personal excellence in performance. With that, it is the purpose of the study to measure the self-control, sense of responsibility and respect for others of the performing artists. For it will be used as the baseline to the operation plan of the HEI Performing Arts Office. If performers stay longer in the performing arts group, their state of self-control as well as their sense of responsibility and respect for others, progresses positively. Performing artists in the HEI uphold the value of self-control, sense of responsibility, and respect for others.
\end{abstract}

Keywords Performing Artist, Higher Education Institution, Self-control, Sense of Responsibility, Respect for Others, Performing Arts

\section{Introduction}

Student performers who would like to be part of the performing arts group already possess the skills required for them to be part of the group. Skills, however, are not enough to become a good performer. Rather, these should be complemented by a positive attitude. This means that a performer should possess the following desirable emotional traits: a) very good self-control; b) sense of responsibility, and c) respect for others. According to Cassidy, as is extracted from the book of Lopez et al. [1] entitled Music, Arts, Physical Education, and Health, any action that a person wants to achieve that is considered his or her best action should be paired with a positive attitude and not merely with scientific knowledge or skills. The moment students become part of the performing arts group they should start to take full responsibility of themselves and begin to refrain from making excuses [2]. According to Tracy [3], people cannot control what development they will undergo after joining a group, but they can control their outlook towards such development. This suggests that student performers should learn to master changes rather than tolerate changes in mastering them. It is given that student performers are full-time students and at the same time full-time performers of the institution where they are enrolled in. It is the responsibility of student performers to maintain a balance between their role as students in an institution, and their responsibilities as members of the performing arts group.

Members of any of the performing arts groups have the responsibility to be present at regular classes, to achieve good grades, and at the same time, to attend rehearsals and performances. Attending rehearsals enable them to further cultivate their skills and allows them to form a proficient group. Also, attending rehearsals helps the performers build strong character, thereby becoming performers with self-control, sense of responsibility, and respect for others. According to Lopez et al. [1], for student performers, to become successful, they should possess the following emotional and social attributes: self-control, sense of responsibility, respect for others, self-confidence, sportsmanship, teamwork, and leadership. Emotional traits or attributes pertain to feelings, thoughts, and behavior of every individual; whereas, social traits or attributes refer to their capacity for socialization or interaction with one another. These components of attitude should be present in every student performer because they are the key to becoming a successful performer and at the same time a successful student. In any given performing arts group competition, other than having the skills needed in the competition and the knowhow of the presentation, it is also a must that a performer should possess positive attitude or 
emotional stability.

According to Cassidy, as is extracted from the book of Lopez et al. [1] entitled Music, Arts, Physical Education, and Health, in order to achieve one's best action, one should carry it out by having both scientific knowledge and positive attitude. All performers of the performing arts group should instill in their hearts and minds the value of discipline for it boils down to everything they do before, during, and after their performances. This sense of discipline must be coupled with desirable social, emotional, and spiritual traits as this would help them achieve their best action or goal as performers. Moreover, performers' attitude is related to self-image and social acceptance [4]. In an attempt to maintain a positive self-image, people's responses tend to be influenced by the need for social desirability. They may not well tell about their real thoughts and feelings nor would they flaunt their true attitudes, but rather respond in a way that they feel socially acceptable.

A performer, even during regular activity, should value his or her personality. Character, attitude, responsibility, and ethics (CARE), according to the University Interscholastic League [5], are the qualities that an individual should possess. Character refers to a certain quality people possess that shapes the way they live their lives and affects the manner in which oth-er people view them. People who display good character are honest with themselves and others, act with a high level of integrity, and treat others with respect even when they disagree with their views. A high level of character creates a positive image of a person in the eyes of others as well as reflects favorably about one's program. Character is the most important quality a person must possess in order to show good sportsmanship. It affects the decisions a person makes and the way he or she is seen by others. A positive attitude is essential when participating in athletics and other school-sponsored activities. Attitude is the disposition that a person shows when reacting to situations, whether they are positive or negative. People with a positive attitude are able to interact with others and respond to adversity in a healthier manner. Taking responsibility is one of the essential qualities of good sportsmanship. Being responsible is to accept one's actions and show awareness of how one's decisions affect others. It is always very important that one conducts himself or herself with pride and takes responsibility for himself or herself and his or her school. A person's ethics can be seen by the way he or she reacts when faced with situations that take his or her integrity and judgment into account. Displaying a high level of ethical behavior is essential when participating in performances and rehearsals. Whether one is a performer, trainer, fan, or administrator, it is his or her responsibility to always conduct himself or herself in an ethical manner that will help promote the goals of the university's performing arts group.

According to the Successful Grownup [6], there are 20 characteristics that healthy and emotionally prepared persons or performers possess and they are the following:

1. Emotionally healthy people are connected; they recognize and believe that everything and everyone is connected. As a result, they engage in actions that preserve and benefit all of humanity. They understand that hurting someone is no different than hurting themselves.

2. They have a conscience. They do the right thing even when no one is looking. They feel guilty and remorseful if they do something that is hurtful, dishonest, or unethical. They understand that the means are always as important as the end. They care, and their actions reflect that.

3. They can be quiet. They can spend time in solitude and quietude, and enjoy it. They recognize the need to recharge, to contemplate, and to be in tune with them.

4. Their self-talk is affirming. They value themselves without being narcissistic. They recognize their talents, contributions, and worth. They are kind to themselves and avoid masochism of any kind.

5. They are self-disciplined. They are able to create goals and sustain the actions necessary to meet them. They have rules of conduct that they uphold, and they follow through on what they promise.

6. They are self-aware. They spend time in contemplative inner examination. They have insight into themselves, and they delve into their real feelings, motives, patterns, values, and beliefs. They understand that ignorance is not bliss, and they engage in self-examination regularly.

7. They have strong values. They have defined values that they live by. Their values most often include respect for others, honesty, keeping their word, kindness, a strong work ethic, and harmlessness, abhorrence of cheating or swindling, and fairness.

8. They are flexible. They can change directions when the situation calls for it. They are able to deal with unforeseen circumstances, meet challenges that appear, assess and reassess as they go, and pivot when necessary.

9. They have a big picture view. They operate with whole pictures, meaning, and they understand the interrelatedness of things. Any action creates a cascade of reactions that have consequences that create further reactions. They consider the long-term consequences of choices based on a whole and complete picture of reality in any given moment.

10. They are able to love. They can truly care for and be attached to another human being. They are able to consider the best interests of others in relationships, and act to support and encourage those they love. They are not competitive, violent, selfish, or deceitful in relationships.

11. They can set boundaries. Just as emotionally healthy people can love and stretch themselves to give to 
those they love, they are equally able to place boundaries on people and situations that are abusive, harmful, or toxic. They value themselves and know when to draw the line on unwanted or toxic behavior.

12. They use language to truly communicate. Language is used to directly express thoughts and feelings so that others can understand clearly who they are, what their intent is, how they perceive things, and what they mean. They do not use language to manipulate or deceive, but rather to truly communicate and foster understanding.

13. They take care of their bodies. They have respect for their bodies, and express this through good diet and regular exercise. They understand that a healthy body supports their capacity to live optimally, succeed, engage in creative thinking, and age well. They understand the correlation between food, exercise, and mood stability.

14. They are responsible. They feel $100 \%$ responsible for their lives, their choices, and their own success in all areas. They do not blame others, their history, or their circumstances for failure, but rather take action to create the circumstances and situations they desire. They live up to their obligations to the best of their ability.

15. They have a work ethic. They expect to work, embrace it, and make the most of it. They do not expect others to take care of them.

16. They have purpose and meaning. Research has shown that people who live with purpose live longer. Emotionally healthy people seek and know their purpose and pursue it. They seek meaning in life and look beyond the day-to-day experiences to dig deeper into the why of their existence.

17. They are proactive rather than reactive. They strive to take action to facilitate the tasks that required them, as well as to pursue their goals. They look ahead rather than wait for things to happen that leave them reeling with little to no control. They seek progress and proactively complete the actions to make it .

18. They can delay gratification and control their impulses. Emotionally healthy people have a good balance between their emotions and their thinking. They use their brains and cognition to help them make sound decisions. They have what is called "executive function," meaning that they can stand back and look at a situation objectively before taking action. They can work toward a goal over time, and can control their emotions in the process to make steady progress.

19. They can plan, organize, and prioritize. They know how to pluck out the most important aspects of living, and pursue those. They can make a plan, organize the steps to facilitate it, and prioritize the order of execution. They have a hand on the different areas of their lives and the activities involved in each of them.
20. They are resilient. Most importantly, emotionally healthy people are resilient and can bounce back from loss or failure. They feel deeply but can process their emotions and make the best of situations as they come, often finding the silver lining. They learn from mistakes, and then move on. Moreover, a person with high emotional intelligence or who possesses self-control, sense of responsibility, and respect for others has the following qualities:

1) Self-awareness - It is a very important trait that, unfortunately, many people lack; however, people with high emotional intelligence are aware of their advantages and their flaws. They will not overrate themselves, neither will they underestimate themselves; they appreciate the fact that they still have to learn things. People with high emotional intelligence are not afraid of their weaknesses.

2) Optimism - People with high emotional intelligence tend to focus on the positive aspects of life. This does not mean that they do not care about the bad news, but that they consciously decide not to spend a lot of their time and energy focusing on problems. Rather, they look at the bright side of a situation and look for solutions to a problem. These people focus on what they are able to do and that which is within their control.

3) Curiosity - Curiosity is one of the most common traits that people with high emotional intelligence have. They are curious about everything, especially, about people they do not know. They love meeting new people or exploring new places and learning new things about life. They also naturally tend to ask lots of questions after they have been introduced to someone. That is because they have a certain degree of empathy, one of the main components of emotional intelligence.

4) Understanding - Empathy helps people with high emotional intelligence to become the best friends. That is because they can truly understand other people's problems. They usually tune into other people's emotions and can adapt to unspoken social cues. They can also see the interpersonal interactions within groups and larger organizations.

5) Accuracy - All people experience emotions, but only a select few can accurately identify them as they occur. Research shows that only $36 \%$ of people can do this, which is problematic because unlabeled emotions often go misunderstood, which may lead to irrational choices and counterproductive actions. People with high emotional intelligence have a robust emotional vocabulary, because they master their emotions. 
6) Presence of mind - This means that people with high emotional intelligence do not take fear so seriously. On the contrary, they understand that fear is something normal, but they need to let it pass. Fear is just a way for the mind to make one consider what is going on, so one can keep it in check. One should not be reckless; however, he or she should reconsider his or her fears and try to face them. And that is what emotionally intelligent people do.

7) Motivation - People with a high emotional intelligence are willing to defer immediate results for long-term success. They are highly productive, love a challenge, and are effective in whatever they do. On the contrary, they hate being bored, so they are constantly trying to have something that keeps them motivated. This proves that intellectual intelligence alone is not enough for a person to succeed in his or her life.

8) Emotional strength - Emotionally intelligent people are familiar with emotions, including the difficult ones. They recognize when they are anxious or exhausted and put off important decisions until they are calmer and better rested. Those with high emotional intelligence allow for difficult emotions and accept them as a part of life. Allowing negative feelings to surface fully into awareness with acceptance and non-judgment fosters self-knowledge and enhances one's sense of purpose.

9) Calmness - Emotionally intelligent people are not obsessed with future events outside of their control. They are comfortable living in a world that does not come with a crystal ball, because life is meant to be an exciting adventure (not a scripted routine). They are okay with their present and past and they cannot wait to face the future.

10) Listening skills - Most people fall into the habit of thinking of a response, while others are speaking instead of actively listening. Emotionally strong leaders avoid that trap, realizing that they need to understand not only the content of what others are saying, but also pick up the feelings behind the words that are being spoken. The emotions behind the words are often more important than the words spoken. It is only when those emotions are acknowledged that people feel that they are being heard. Often, complaints are about situations that leaders can do little to change.
People are often aware of that, but still have the need to feel heard [7] and [8].

Acting optimistically, according to the journal of teachers, may result to positive output. Firmness shows that they respect themselves and that they have self-control, while kindness shows respect for others. This only indicates that by simply having a positive attitude in life, everything will be all right. A person with positive attitude owns the value of self-control, sense of responsibility, sportsmanship, discipline, respect for others, etc.

According to Gurian [9], the ultimate goal of discipline is to help individuals internalize the value of self-control and not to have them merely obey what is said by the authority. Developing self-control is a gradual process. It depends on the person how fast he or she develops the value of self-control. Practicing it is, however, a process that every individual must learn to master.

Given the proper training and appropriate activities provided by the trainers and the head of the performing arts group to their respective performers, it remains a puzzle why some performers still venture into forming destructive attitude. It is from this perspective that this study was directed to measure the performing artists' self-control, sense of responsibility, and respect for others. Its findings are not only deemed important for the performers, head of the performing arts group, and the trainers, they will also serve as bases for the drafting of the Performing Arts Office's operational plan.

The theoretical framework presents the theory of Rosalind Cassidy, UCLA professor emeritus, that best action is equal to scientific knowledge plus positive attitude. In this study, the scientific knowledge component is represented by the performing artists in an HEI who already possess the skills and knowledge needed in their respective performing groups plus the positive attitude of the performers namely: self-control, sense of responsibility, and respect for others which are equivalent to producing successful performing artists. The latter component of a successful performer was measured in terms of descriptions of the commonality and differences of the attitude of the performing group, gender, and years of service within the group which were gained through the use of Dell's Attitude Scale [10]. The result served as the basis for the drafting of the Performing Arts Office's operational plan. Does gender have an impact on the emotional traits of the performers? How about the number of years of service rendered in the group? Do all the performing groups share the same traits or are there groups that excel in terms of emotional traits? 

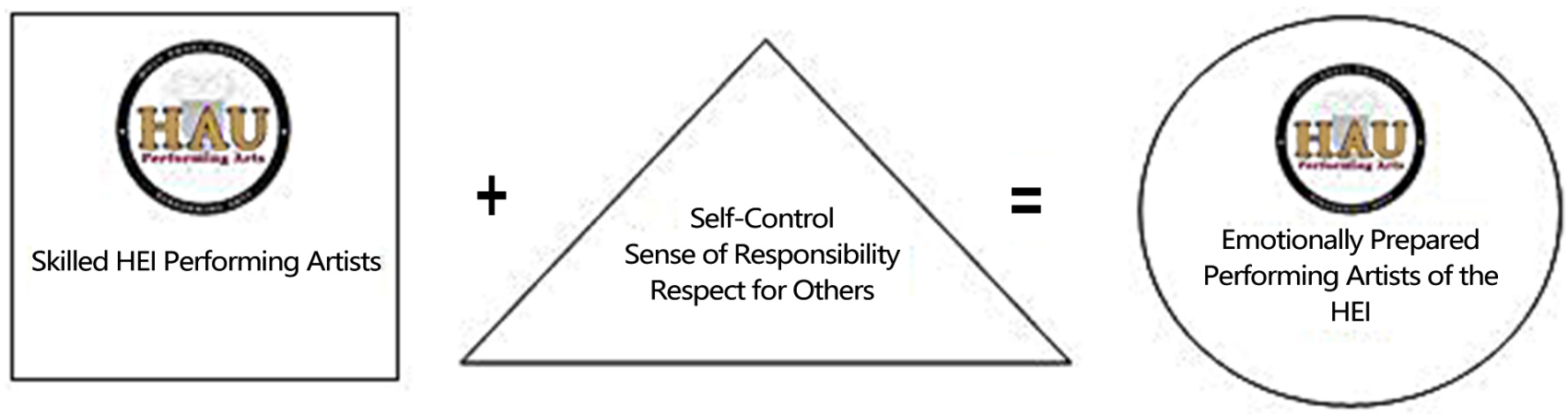

Figure 1. Paradigm of the study

The following are the hypotheses of this study expressed in the null:

Ho: There is no significant difference between the performers' self-control, sense of responsibility and respect for others in terms of gender.

Ho: There is no significant difference between the HEI performers' emotional intelligence in terms of number of year(s) of service.

Ho: There is no significant difference between the HEI performers' emotional intelligence in terms of age.

The study aimed to present some inputs for the enhancement of the Higher Education Institution's Performing Arts Office's Operational Plan by measuring the performers' self-control, sense of responsibility, and respect for others. Specifically, it attempted to answer the following questions:

1. How many the demographic profile of the performing artists in the HEI were described in terms of:

1.1 Gender,

1.2 Years of Service, and

1.3 Age?

2. How many the HEI's performing artists' self-control, sense of responsibility, and respect for others were described when grouped according to:
2.1 Gender,
2.2 Year of Service, and
2.3 Age?

3. Is there a significant difference between the level of self-control, sense of responsibility, and respect for others of the performing artists in the HEI when grouped according to:
3.1 Gender,
3.2 Year of Service, and
3.3 Age?

\section{Method}

This study is a descriptive type of research. It describes the nature of the situation as it exists. As is defined by Adanza [11], descriptive research is an investigation, which describes and interprets what something is. It is concerned with condition and a relationship that exist, practices that prevail and beliefs and processes that are going on, effects that are being felt, or trends that are developing. Also, according to Airasian et al. [12], a descriptive research involves collection of data in order to answer questions concerning the current status of a subject under study. This study is descriptive for it consists of fact finding and pursuit of answers through a series of steps starting with an analysis of the problem, definition of the problem, adaptation of techniques for gathering data, interpretation, and description of data in precise terms.

In the preparation of the questionnaire, the descriptive type of research was utilized. After the identification of the problem, the researcher conducted extensive library research and analysis of the different references, journals, and instructional materials, which served as reference materials in the preparation of the questionnaire and related literature and studies. Interview and consultation were conducted with people who are knowledgeable in the study.

A standardized questionnaire based on a foreign setting was revised by the researcher to make it localized. The researcher made questionnaire was given to the experts for final evaluation vis-à-vis the appropriateness and level of understandability of the questions. Also, the questionnaire made by the researcher was pilot tested to another set of performers; after which, it was analyzed by using Cronbach's alpha. The finalized form was distributed among the respondents of the study. The questionnaire focused on the performers' self-control, sense of responsibility, and respect for others. As soon as the researcher was able to retrieve the entire set of questionnaires, the responses of the respondents were tallied and analyzed.

The participants of the study were the male and female performing artists in the Higher Education Institution in Angeles City. The researcher used purposive sampling technique in identifying the respondents to ensure the validity of the study and to capture precise, clear-cut answers from the respondents. Using this sampling technique, the researcher was able to have all the HEI's male and female performing artists as respondents, totaling to 52 male and 43 female performers across all performing groups. 
The table below presents the total number of respondents per performing arts group.

Table 1. Performing Arts Group and Total Number of Male and Female Performers

\begin{tabular}{lccc}
\hline Performing Arts Group & Male & Female & Total \\
\hline Brass Band & 12 & 10 & 22 \\
\hline Chorale & 13 & 12 & 25 \\
\hline Dance Theatre & 8 & 4 & 13 \\
\hline Repertory & 6 & 5 & 11 \\
\hline Rondalla & 10 & 9 & 19 \\
\hline Strings & 3 & 3 & 6 \\
\hline Total & 52 & 43 & 95 \\
\hline
\end{tabular}

To draw the pertinent data and information needed to answer the specific problem, the researcher utilized the localized questionnaire. In order for the researcher to measure the HEI's performing artists' self-control, sense of responsibility, and respect for others, the researcher made use of the Dell Attitude Scale questionnaire as its major tool. This is a standardized test that measures the attitude of self-control, sense of responsibility, and respect for others. The standardized questionnaire underwent a Flanagan discriminatory index for validity test and got a .91 reliability coefficient. From the given questionnaire, the researcher made a revised form in order to localize the setting. The revised questionnaire was subjected for critique by experts for the final evaluation of the appropriateness and the level of understandability of the questions. It was afterwards pilot tested to another set of performers. The revised questionnaire got a .87 Cronbach alpha result. Assessment of the questionnaire was done using a four-point scale which is as follows: 4 - Strongly Agree; 3 - Agree; 2 - Disagree; 1 - Strongly Disagree[13].

After identifying the problem, the researcher conducted an intensive library research and analysis of the reference materials, journals, websites, and instructional materials, which served as reference materials in analyzing the emotional traits of the performers. The researcher also conducted an interview and consultation with a psychologist, a trainer, and some performers.

Fifty-two (52) male and forty-three (43) female totaling to ninety-five (95) performers served as the respondents of the study. The selection was done following the purposive sampling technique to ensure the validity of the study and to capture precise, clear-cut answers from the respondents. The questionnaire was administered personally by the researcher to the entire performing arts group per day of meeting so that if there would be questions in relation to the questionnaire, it would be easy to discuss them and promptly entertain the respondents' queries. This was aimed at achieving clear and precise answers from the respondents. The program of administering the questionnaire was scheduled as follows: a) Monday Choir, Strings, and Parade Band; b) Tuesday - Dancers and
Repertory (Actors), and c) Wednesday - Rondalla.

The results that were gathered from the questionnaire were tallied, tabulated, analyzed, and interpreted. The percentage, mean rating, independent samples T-Test and One-way Analysis of Variance were employed in the statistical treatment of the data. In order to facilitate the analysis and interpretation of data, the researcher constructed arbitrary sets of graduated four-point scale rating guides, to wit: for self-control - very low, low, high, and very high; for sense of responsibility - not at all responsible, somewhat responsible, mostly responsible, and completely responsible; and for respect for others - not at all respectful, somewhat respectful, mostly respectful, and completely respectful.

\section{Results}

\subsection{Description of the Demographic Profile of the Performing Artists}

Table 2 presents the demographic profile of the participants of the study. There are 43 female and 52 male respondents totaling to 95 participants across performing groups. In terms of number of years of service, the performers' length of service across performing groups ranges from one (1) year to five (5) years. There are 31 members who have been serving the group for three (3) years; twenty-two (22) members have been serving the group for four (4) years; seventeen (17) members have been serving for two (2) years; fifteen 15 members have been with the group for one (1) year, and 10 members have been serving the group for five (5) years. The ages of the performers range from 18 to 29 years. There are 35 performers whose age is 19 years old; twenty-four (24) of them are 20 years old; there are 22 performers whose age is 18 years old; eight (8) of the performers are aged 21; two (2) members are 24 years old; 1 performer's age is 22 ; there is one (1) member who is 25 years old and another one (1) who is 29 years old.

\subsection{Description of the Emotional Intelligence of the Performing Artists in the HEI in Terms of Self-control, Sense of Responsibility and Respect for Others}

\subsubsection{In Terms of Gender}

Table 3 presents the self-control, sense of responsibility, and respect for others of the performers in terms of gender. As for self-control, both male and female performers possess a very high level of self-control with a mean rating of 3.31 for male and 3.28 for female, while in terms of sense of responsibility and respect for others, both genders were found to be mostly responsible and mostly respectful with mean ratings ranging from 2.96 to 3.25 . 
Table 2. Demographic Profile of the Participants of the Study

\begin{tabular}{|c|c|c|c|c|c|c|c|c|}
\hline & \multicolumn{8}{|c|}{ PERFORMING GROUP } \\
\hline & $\begin{array}{l}\text { BRASS } \\
\text { BAND }\end{array}$ & CHORALE & $\begin{array}{c}\text { DANCE } \\
\text { THEATRE }\end{array}$ & REPERTORY & RONDALLA & STRINGS & Total & $\%$ \\
\hline \multicolumn{9}{|l|}{ GENDER } \\
\hline FEMALE & 10 & 12 & 4 & 5 & 9 & 3 & 43 & 45.26 \\
\hline MALE & 12 & 13 & 8 & 6 & 10 & 3 & 52 & 54.74 \\
\hline \multicolumn{9}{|l|}{ YEARS OF SERVICE } \\
\hline 1 & 1 & 3 & 4 & & 5 & 2 & 15 & 15.79 \\
\hline 2 & 1 & 3 & & 11 & 2 & & 17 & 17.89 \\
\hline 3 & 5 & 11 & 3 & & 11 & 1 & 31 & 32.63 \\
\hline 4 & 10 & 5 & 5 & & & 2 & 22 & 23.16 \\
\hline 5 & 5 & 3 & & & 1 & 1 & 10 & 10.53 \\
\hline \multicolumn{9}{|l|}{ AGE } \\
\hline 18 & 3 & 10 & & 2 & 7 & & 22 & 23.16 \\
\hline 19 & 4 & 6 & 6 & 6 & 10 & 3 & 35 & 36.84 \\
\hline 20 & 6 & 5 & 6 & 3 & 2 & 2 & 24 & 25.26 \\
\hline 21 & 3 & 4 & & & & 1 & 8 & 8.42 \\
\hline 22 & 1 & & & & & & 1 & 1.05 \\
\hline 23 & 1 & & & & & & 1 & 1.05 \\
\hline 24 & 2 & & & & & & 2 & 2.11 \\
\hline 25 & 1 & & & & & & 1 & 1.05 \\
\hline 29 & 1 & & & & & & 1 & 1.05 \\
\hline $\begin{array}{c}\text { TOTAL NO. OF } \\
\text { PARTICIPANTS PER } \\
\text { PERFORMING GROUP }\end{array}$ & 22 & 25 & 12 & 11 & 19 & 6 & 95 & \\
\hline
\end{tabular}

Table 3. Self-Control, Sense of Responsibility, and Respect for Others of Participants in Terms of Gender

\begin{tabular}{|c|c|c|c|c|c|c|c|c|c|c|c|c|}
\hline \multirow{4}{*}{$\begin{array}{l}\text { PERFORMING GROUP } \\
\text { BRASS BAND }\end{array}$} & \multicolumn{4}{|c|}{ SELF-CONTROL } & \multicolumn{4}{|c|}{ SENSE OF RESPONSIBILITY } & \multicolumn{4}{|c|}{ RESPECT FOR OTHERS } \\
\hline & \multicolumn{12}{|c|}{ GENDER } \\
\hline & \multicolumn{2}{|c|}{ M } & \multicolumn{2}{|c|}{$\mathrm{F}$} & \multicolumn{2}{|c|}{ M } & \multicolumn{2}{|c|}{$\mathrm{F}$} & \multicolumn{2}{|c|}{$\mathrm{M}$} & \multicolumn{2}{|c|}{$\mathrm{F}$} \\
\hline & 3.31 & $\mathrm{VH}$ & 3.07 & $\mathrm{H}$ & 2.84 & MR & 2.79 & MR & 3.26 & $\mathrm{CR}$ & 3.07 & MR \\
\hline REPERTORY & 3.32 & $\mathrm{VH}$ & 3.16 & $\mathrm{H}$ & 2.85 & MR & 3.02 & MR & 3.17 & MR & 3.21 & MR \\
\hline RONDALLA & 3.35 & $\mathrm{VH}$ & 3.27 & $\mathrm{VH}$ & 3.09 & MR & 3.02 & MR & 3.26 & $\mathrm{CR}$ & 3.24 & MR \\
\hline CHORALE & 3.37 & $\mathrm{VH}$ & 3.42 & $\mathrm{VH}$ & 3.02 & MR & 2.84 & MR & 3.32 & $\mathrm{CR}$ & 3.34 & $\mathrm{CR}$ \\
\hline DANCE THEATRE & 2.83 & $\mathrm{H}$ & 2.93 & $\mathrm{H}$ & 2.66 & MR & 2.63 & MR & 3.00 & MR & 3.21 & MR \\
\hline STRINGS & 3.67 & $\mathrm{VH}$ & 3.82 & VH & 3.56 & $\mathrm{CR}$ & 3.44 & $\mathrm{CR}$ & 3.43 & $\mathrm{CR}$ & 3.43 & $\mathrm{CR}$ \\
\hline OVER-ALL & 3.31 & $\mathrm{VH}$ & 3.28 & VH & 3.00 & MR & 2.96 & MR & 3.24 & MR & 3.25 & MR \\
\hline
\end{tabular}

Legend: VL - Very Low NAR - Not at all Responsible NAR - Not at all Respectful

L - Low SR - Somewhat Responsible SR - Somewhat Respectful

H - High MR - Mostly Responsible MR - Mostly Respectful

VH - Very High CR - Completely Responsible CR - Completely Respectful

\subsubsection{In Terms of Years of Service}

The state of self-control of the participants in terms of years of service is shown in Table 4. Members who have rendered three (3), four (4), and five (5) years of service with a mean rating of $3.34,3.26$ and 3.48 , respectively, possess a very high level of self-control, while those who have been part of the group for one (1) year obtaining a mean rating of 3.21 and those who have served for two (2) years registering a mean rating of 3.14 were found to possess a high level of self-control.

The participants' sense of responsibility in terms of years of service is shown in Table 5. Members who have been in the group for five (5) years garnered a mean rating of 3.31 and were found to be completely responsible, while those who have spent one (1) year of service garnering a 
mean rating of 3.09 and those who have served the group for two (2) years registering a 2.97 mean rating as well as those who have rendered three (3) years of service with a mean rating of 3.09 and four (4) years of service with a mean rating of 3.06 were found to be mostly responsible.

The respondents' state of respect for others in terms of years of service is shown in Table 6. Those who have served for three (3) years, four (4) years, and five (5) years with a mean rating of $3.27,3.26$, and 3.38 , respectively, are described to be completely respectful, while those who have rendered one (1) year of service with a mean rating of 3.05 and two (2) years of service with a mean rating of 3.06 are mostly respectful of others.

Table 4. State of Self-Control of the Participants in Terms of Years of Service

\begin{tabular}{|c|c|c|c|c|c|c|c|c|c|c|c|}
\hline \multirow{2}{*}{ PERFORMING GROUP } & \multirow{2}{*}{ GENDER } & \multicolumn{10}{|c|}{ YEARS OF SERVICE } \\
\hline & & 1 & & 2 & & 3 & & 4 & & 5 & \\
\hline \multirow{2}{*}{ BRASS BAND } & FEMALE & & & 3.33 & $\mathrm{VH}$ & 3.11 & $\mathrm{H}$ & 3.01 & $\mathrm{H}$ & 3.20 & $\mathrm{H}$ \\
\hline & MALE & 3.07 & $\mathrm{H}$ & & & 3.13 & $\mathrm{H}$ & 3.36 & $\mathrm{VH}$ & 3.30 & $\mathrm{VH}$ \\
\hline \multirow{2}{*}{ CHORALE } & FEMALE & & & 3.33 & $\mathrm{VH}$ & 3.62 & $\mathrm{VH}$ & 3.27 & $\mathrm{VH}$ & & \\
\hline & MALE & 3.16 & $\mathrm{H}$ & 2.08 & $\mathrm{H}$ & 3.67 & VH & 3.33 & VH & 3.49 & $\mathrm{VH}$ \\
\hline \multirow{2}{*}{ DANCE THEATRE } & FEMALE & 2.93 & $\mathrm{H}$ & & & & & 2.93 & $\mathrm{H}$ & & \\
\hline & MALE & 2.91 & $\mathrm{H}$ & & & 2.84 & $\mathrm{H}$ & 2.73 & $\mathrm{H}$ & & \\
\hline \multirow{2}{*}{ REPERTORY } & FEMALE & & & 3.03 & $\mathrm{H}$ & & & & & & \\
\hline & MALE & & & 2.95 & $\mathrm{H}$ & & & & & & \\
\hline \multirow{2}{*}{ RONDALLA } & FEMALE & 3.33 & $\mathrm{VH}$ & & & 3.23 & $\mathrm{H}$ & & & & \\
\hline & MALE & 3.51 & $\mathrm{VH}$ & 3.53 & $\mathrm{VH}$ & 3.38 & $\mathrm{VH}$ & & & 3.33 & $\mathrm{VH}$ \\
\hline \multirow{2}{*}{ STRINGS } & FEMALE & & & & & 3.87 & $\mathrm{VH}$ & 3.73 & VH & 3.87 & $\mathrm{VH}$ \\
\hline & MALE & 3.47 & $\mathrm{VH}$ & & & 3.73 & $\mathrm{VH}$ & & & 3.80 & $\mathrm{VH}$ \\
\hline OVER-ALL & & 3.21 & $\mathrm{H}$ & 3.14 & $\mathrm{H}$ & 3.34 & $\mathrm{VH}$ & 3.26 & VH & 3.48 & $\mathrm{VH}$ \\
\hline
\end{tabular}

Legend: VL - Very Low

L - Low

SH - Slightly High

$\mathrm{H}$ - High

Table 5. State of Sense of Responsibility of the Participants in Terms of Years of Service

\begin{tabular}{|c|c|c|c|c|c|c|c|c|c|c|c|}
\hline \multirow{2}{*}{ PERFORMING GROUP } & \multirow{2}{*}{ GENDER } & \multicolumn{10}{|c|}{ YEARS OF SERVICE } \\
\hline & & 1 & & 2 & & 3 & & 4 & & 5 & \\
\hline \multirow{2}{*}{ BRASS BAND } & FEMALE & & & 3.21 & MR & 2.79 & MR & 3.16 & MR & 3.05 & MR \\
\hline & MALE & 3.05 & MR & & & 3.26 & $\mathrm{CR}$ & 3.04 & MR & 3.24 & $\mathrm{CR}$ \\
\hline \multirow{2}{*}{ CHORALE } & FEMALE & & & 2.68 & MR & 2.83 & MR & 3.01 & MR & & \\
\hline & MALE & 3.12 & MR & 2.58 & MR & 3.31 & $\mathrm{CR}$ & 2.68 & MR & 3.47 & $\mathrm{CR}$ \\
\hline \multirow{2}{*}{ DANCE THEATRE } & FEMALE & 2.63 & MR & & & & & 2.63 & MR & & \\
\hline & MALE & 2.58 & MR & & & 2.68 & MR & 2.79 & MR & & \\
\hline \multirow{2}{*}{ REPERTORY } & FEMALE & & & 3.13 & MR & & & & & & \\
\hline & MALE & & & 2.96 & MR & & & & & & \\
\hline \multirow{2}{*}{ RONDALLA } & FEMALE & 2.97 & MR & & & 3.11 & MR & & & & \\
\hline & MALE & 3.19 & MR & 3.00 & MR & 3.12 & MR & & & 3.26 & $\mathrm{CR}$ \\
\hline \multirow{2}{*}{ STRINGS } & FEMALE & & & & & 3.53 & $\mathrm{CR}$ & 3.58 & $\mathrm{CR}$ & 3.58 & $\mathrm{CR}$ \\
\hline & MALE & 3.58 & $\mathrm{CR}$ & & & 3.58 & $\mathrm{CR}$ & 0.00 & & 3.16 & MR \\
\hline OVERALL & & 3.09 & MR & 2.97 & MR & 3.09 & MR & 3.06 & MR & 3.31 & $\mathrm{CR}$ \\
\hline
\end{tabular}

Legend: NAR - Not at all Responsible

SR - Somewhat Responsible

MR - Mostly Responsible

CR - Completely Responsible 
Table 6. State of Respect for Others of the Participants in Terms of Years of Service

\begin{tabular}{|c|c|c|c|c|c|c|c|c|c|c|c|}
\hline \multirow{2}{*}{ PERFORMING GROUP } & \multirow{2}{*}{ GENDER } & \multicolumn{10}{|c|}{ YEARS OF SERVICE } \\
\hline & & 1 & & 2 & & 3 & & 4 & & 5 & \\
\hline \multirow{2}{*}{ BRASS BAND } & FEMALE & & & 3.14 & MR & 2.88 & MR & 3.13 & MR & 3.07 & MR \\
\hline & MALE & 2.36 & MR & & & 3.50 & $\mathrm{CR}$ & 3.57 & $\mathrm{CR}$ & 3.18 & MR \\
\hline \multirow{2}{*}{ CHORALE } & FEMALE & & & 3.07 & MR & 3.30 & $\mathrm{CR}$ & 3.29 & $\mathrm{CR}$ & & \\
\hline & MALE & 3.05 & MR & 2.57 & MR & 3.36 & $\mathrm{CR}$ & 3.29 & $\mathrm{CR}$ & 3.62 & $\mathrm{CR}$ \\
\hline \multirow{2}{*}{ DANCE THEATRE } & FEMALE & 3.21 & MR & & & & & 3.21 & MR & & \\
\hline & MALE & 2.98 & MR & & & 3.24 & MR & 2.68 & MR & & \\
\hline \multirow{2}{*}{ REPERTORY } & FEMALE & & & 3.23 & MR & & & & & & \\
\hline & MALE & & & 3.08 & MR & & & & & & \\
\hline \multirow{2}{*}{ RONDALLA } & FEMALE & 3.29 & $\mathrm{CR}$ & & & 3.24 & MR & & & & \\
\hline & MALE & 3.29 & $\mathrm{CR}$ & 3.14 & MR & 3.09 & MR & & & 3.36 & $\mathrm{CR}$ \\
\hline \multirow{2}{*}{ STRINGS } & FEMALE & & & & & 3.43 & $\mathrm{CR}$ & 3.43 & $\mathrm{CR}$ & 3.43 & $\mathrm{CR}$ \\
\hline & MALE & 3.43 & $\mathrm{CR}$ & & & 3.43 & $\mathrm{CR}$ & & & 3.43 & $\mathrm{CR}$ \\
\hline OVERALL & & 3.05 & MR & 3.06 & MR & 3.27 & $\mathrm{CR}$ & 3.26 & $\mathrm{CR}$ & 3.38 & $\mathrm{CR}$ \\
\hline
\end{tabular}

Legend: NAR - Not at all Respectful

SR - Somewhat Respectful

MR - Mostly Respectful

CR - Completely Respectful 
3.2.3. In Terms of Age

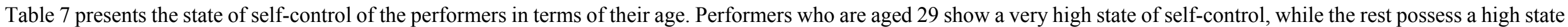
of self-control.

Table 7. State of Self-Control of the Participants in Terms of Age

\begin{tabular}{|c|c|c|c|c|c|c|c|c|c|c|c|c|c|c|c|c|c|c|c|}
\hline \multirow{2}{*}{$\begin{array}{l}\text { PERFORMING } \\
\text { GROUP }\end{array}$} & \multirow{2}{*}{ GENDER } & \multicolumn{18}{|c|}{$A G E$} \\
\hline & & 18 & & 19 & & 20 & & 21 & & 22 & & 23 & & 24 & & 25 & & 29 & \\
\hline \multirow{2}{*}{ BRASS BAND } & FEMALE & 3.27 & $\mathrm{VH}$ & 3.30 & $\mathrm{VH}$ & 3.00 & $\mathrm{H}$ & 3.21 & $\mathrm{H}$ & & & 2.93 & $\mathrm{H}$ & & & & & & \\
\hline & MALE & 3.33 & $\mathrm{VH}$ & 3.60 & VH & 3.43 & $\mathrm{VH}$ & 3.13 & $\mathrm{H}$ & 3.13 & $\mathrm{H}$ & & & 2.83 & $\mathrm{H}$ & 3.20 & $\mathrm{H}$ & 3.40 & $\mathrm{VH}$ \\
\hline \multirow{2}{*}{ CHORALE } & FEMALE & 3.31 & & & & 3.18 & & 3.04 & $\mathrm{H}$ & & & & & & & & & & \\
\hline & MALE & 3.23 & $\mathrm{H}$ & 3.02 & $\mathrm{H}$ & 3.20 & $\mathrm{H}$ & 2.87 & $\mathrm{H}$ & & & & & & & & & & \\
\hline \multirow{2}{*}{ DANCE THEATRE } & FEMALE & & & & & 2.93 & $\mathrm{H}$ & & & & & & & & & & & & \\
\hline & MALE & & & 2.87 & $\mathrm{H}$ & 2.73 & $\mathrm{H}$ & & & & & & & & & & & & \\
\hline \multirow{2}{*}{ REPERTORY } & FEMALE & 2.73 & $\mathrm{H}$ & 2.87 & $\mathrm{H}$ & 3.07 & $\mathrm{H}$ & & & & & & & & & & & & \\
\hline & MALE & 2.87 & $\mathrm{H}$ & 2.93 & $\mathrm{H}$ & 3.13 & $\mathrm{H}$ & & & & & & & & & & & & \\
\hline \multirow{2}{*}{ RONDALLA } & FEMALE & 3.12 & $\mathrm{H}$ & 3.27 & VH & & & & & & & & & & & & & & \\
\hline & MALE & & & 3.23 & $\mathrm{H}$ & 3.00 & $\mathrm{H}$ & & & & & & & & & & & & \\
\hline \multirow{2}{*}{ STRINGS } & FEMALE & 3.73 & VH & 3.87 & $\mathrm{VH}$ & 3.87 & VH & & & & & & & & & & & & \\
\hline & MALE & 3.73 & $\mathrm{VH}$ & 3.47 & $\mathrm{VH}$ & 3.80 & $\mathrm{VH}$ & & & & & & & & & & & & \\
\hline OVERALL & & 3.24 & $\mathrm{H}$ & 3.19 & $\mathrm{H}$ & 3.21 & $\mathrm{H}$ & 3.06 & $\mathrm{H}$ & 3.13 & $\mathrm{H}$ & 2.93 & $\mathrm{H}$ & 2.83 & $\mathrm{H}$ & 3.20 & $\mathrm{H}$ & 3.40 & $\mathrm{VH}$ \\
\hline
\end{tabular}

Legend: VL - Very Low

L - Low

SH - Slightly High

$\mathrm{H}$ - High 
Table 8 presents the state of sense of responsibility of the performers in terms of their age. Performers whose age is 29 are completely responsible, while the rest are mostly responsible

Table 8. State of Sense of Responsibility of the Participants in Terms of Age

\begin{tabular}{|c|c|c|c|c|c|c|c|c|c|c|c|c|c|c|c|c|c|c|c|}
\hline \multirow{2}{*}{$\begin{array}{l}\text { PERFORMING } \\
\text { GROUP }\end{array}$} & \multirow{2}{*}{ GENDER } & \multicolumn{18}{|c|}{ AGE } \\
\hline & & 18 & & 19 & & 20 & & 21 & & 22 & & 23 & & 24 & & 25 & & 29 & \\
\hline \multirow{2}{*}{ BRASS BAND } & FEMALE & 2.89 & MR & 3.08 & MR & 3.16 & MR & 3.05 & MR & & & 2.63 & MR & & & & & & \\
\hline & MALE & 3.21 & MR & 3.21 & MR & 3.08 & MR & 3.21 & MR & 2.95 & MR & & & 2.58 & MR & 3.47 & $\mathrm{CR}$ & 3.26 & $\mathrm{CR}$ \\
\hline \multirow{2}{*}{ CHORALE } & FEMALE & 2.96 & MR & & & 2.84 & MR & 2.91 & MR & & & & & & & & & & \\
\hline & MALE & 3.42 & $\mathrm{CR}$ & 2.89 & MR & 3.53 & $\mathrm{CR}$ & 3.37 & $\mathrm{CR}$ & & & & & & & & & & \\
\hline \multirow{2}{*}{$\begin{array}{l}\text { DANCE } \\
\text { THEATRE }\end{array}$} & FEMALE & & & & & 2.63 & MR & & & & & & & & & & & & \\
\hline & MALE & & & 2.63 & MR & 2.79 & MR & & & & & & & & & & & & \\
\hline \multirow{2}{*}{ REPERTORY } & FEMALE & 3.11 & MR & 3.13 & MR & 2.79 & MR & & & & & & & & & & & & \\
\hline & MALE & 3.00 & MR & 3.12 & MR & 3.11 & MR & & & & & & & & & & & & \\
\hline \multirow{2}{*}{ RONDALLA } & FEMALE & 3.06 & MR & 3.21 & MR & & & & & & & & & & & & & & \\
\hline & MALE & & & 3.12 & MR & 3.16 & MR & & & & & & & & & & & & \\
\hline \multirow{2}{*}{ STRINGS } & FEMALE & 3.58 & $\mathrm{CR}$ & 3.53 & $\mathrm{CR}$ & 3.58 & MR & & & & & & & & & & & & \\
\hline & MALE & 3.58 & $\mathrm{CR}$ & 3.16 & MR & 3.58 & $\mathrm{CR}$ & & & & & & & & & & & & \\
\hline OVERALL & & 3.19 & MR & 3.05 & MR & 3.14 & MR & 3.14 & MR & 2.95 & MR & 2.63 & MR & 2.58 & MR & 3.47 & $\mathrm{CR}$ & 3.26 & $\mathrm{CR}$ \\
\hline
\end{tabular}

Legend: NAR - Not at all Responsible SR - Somewhat Responsible

MR - Mostly Responsible $\quad$ CR - Completely Responsible 


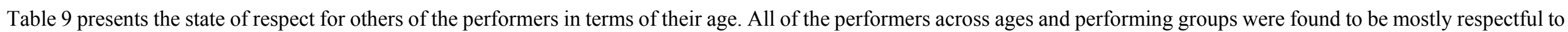
others.

Table 9. State of Respect for Others of the Participants in Terms of Age

\begin{tabular}{|c|c|c|c|c|c|c|c|c|c|c|c|c|c|c|c|c|c|c|c|}
\hline \multirow{2}{*}{ PERFORMING GROUP } & \multirow{2}{*}{ GENDER } & \multicolumn{18}{|c|}{ AGE } \\
\hline & & 18 & & 19 & & 20 & & 21 & & 22 & & 23 & & 24 & & 25 & & 29 & \\
\hline \multirow{2}{*}{ BRASS BAND } & FEMALE & 2.86 & MR & 3.00 & MR & 3.14 & MR & 3.07 & MR & & & 2.79 & MR & & & & & & \\
\hline & MALE & 3.36 & $\mathrm{CR}$ & 3.49 & $\mathrm{CR}$ & 3.68 & $\mathrm{CR}$ & 3.14 & MR & 3.00 & MR & & & 2.79 & MR & 3.21 & MR & 2.79 & MR \\
\hline \multirow{2}{*}{ CHORALE } & FEMALE & 3.29 & & & & 3.24 & MR & 3.05 & MR & 3.00 & MR & & & & & & & & \\
\hline & MALE & 3.30 & & 3.26 & $\mathrm{CR}$ & 3.43 & MR & 3.50 & $\mathrm{CR}$ & 3.00 & $\mathrm{CR}$ & & & & & & & & \\
\hline \multirow{2}{*}{ DANCE THEATRE } & FEMALE & & & & & 3.21 & MR & & & & & & & & & & & & \\
\hline & MALE & & & 3.12 & MR & 2.68 & MR & & & & & & & & & & & & \\
\hline \multirow{2}{*}{ REPERTORY } & FEMALE & 3.21 & MR & 3.21 & MR & 2.64 & MR & & & & & & & & & & & & \\
\hline & MALE & 3.00 & MR & 3.10 & MR & 3.14 & MR & & & & & & & & & & & & \\
\hline \multirow{2}{*}{ RONDALLA } & FEMALE & 3.18 & MR & 3.29 & $\mathrm{CR}$ & & & & & & & & & & & & & & \\
\hline & MALE & & & 3.17 & MR & 3.07 & MR & & & & & & & & & & & & \\
\hline \multirow{2}{*}{ STRINGS } & FEMALE & 3.43 & $\mathrm{CR}$ & 3.43 & $\mathrm{CR}$ & 3.43 & $\mathrm{CR}$ & & & & & & & & & & & & \\
\hline & MALE & 3.43 & $\mathrm{CR}$ & 3.43 & $\mathrm{CR}$ & 3.43 & $\mathrm{CR}$ & & & & & & & & & & & & \\
\hline OVERALL & & 3.22 & MR & 3.25 & MR & 3.19 & MR & 3.19 & MR & 3.00 & MR & 2.79 & MR & 2.79 & MR & 3.21 & MR & 2.79 & MR \\
\hline
\end{tabular}

Legend: NAR - Not at all Respectful SR - Somewhat Respectful

MR - Mostly Respectful CR - Completely Respectful 


\subsection{Significant Difference between the Traits and Emotional Intelligence of One Performing Group and Another Performing Group}

\subsubsection{On Gender}

Table 10 presents the differences between male and female performers' level of self-control, sense of responsibility, and respect for others. At $p<0.5$ level of significance, it is clear that there exists no significant difference between female and male performers' self-control with p-value of 0.797 , sense of responsibility with p-value of .56 , and respect for others with p-value of 1 .

\subsubsection{On Years of Service}

The differences between the performing groups' self-control, sense of responsibility, and respect for others in terms of years of service is presented in Table 11. At $p=$
0.05 level of significance, there exists enough evidence to state that there is no significant difference on performers' self-control with p-value of .40 , sense of responsibility with p-value of .77 , and respect for others with p-value of .79 in terms of the years of service rendered.

\subsubsection{On Age}

The differences between the performing groups' self-control, sense of responsibility, and respect for others in terms of age is presented in Table 12. With a level of significance computed at $=0.05$, there exists enough evidence to state that there is no significant difference on performers' self-control with p-value of .618, neither was there significant difference on performers' sense of responsibility with $\mathrm{p}$-value of .022 ; however, significant differences on the performers' level of respect for others in terms of the age has been revealed with p-value of .007 .

Table 10. Significant Differences between Male and Female Performers' Self-Control, Sense of Responsibility and Respect for Others

\begin{tabular}{ccccccccc}
\hline & Gender & Diff. Mean & Sq. diff. SS & $\mathrm{S}^{2} 1$ & $\mathrm{~S} 2$ & $\mathrm{t}$-value & p-value & Interpretation \\
\hline \multirow{2}{*}{ Self-Control } & Female & 3.07 & 4.93 & 0.35 & & -0.3 & 0.797 & Not Significant \\
\cline { 2 - 9 } & Male & 3.13 & 5.73 & & 0.41 & & & Not Significant \\
\hline \multirow{2}{*}{ Sense of Responsibility } & Female & 2.89 & 3.79 & 0.21 & & 0.59 & 0.56 & \\
\cline { 2 - 10 } & Male & 2.79 & 7.16 & & 0.4 & & & Not Significant \\
\hline \multirow{2}{*}{ Respect for Others } & Female & 3.24 & 1.11 & 0.09 & & 0 & 1 \\
\cline { 2 - 9 } & Male & 3.24 & 1.13 & & 0.09 & & &
\end{tabular}

Table 11. Significant Difference between Performing Groups' Self-Control, Sense of Responsibility, and Respect for Others in Terms of Years of Service

\begin{tabular}{|c|c|c|c|c|c|c|c|c|}
\hline & Years of Service & Mean & $\sum \mathbf{X}$ & $\sum \mathbf{X}^{2}$ & $\begin{array}{l}\text { Std. } \\
\text { Dev. }\end{array}$ & f-ratio value & p-value & Interpretation \\
\hline \multirow{5}{*}{ Self-Control } & 1 & 2.33 & 34.90 & 85.03 & 0.52 & 1.03 & 0.40 & Not significant \\
\hline & 2 & 2.02 & 30.30 & 65.89 & 0.58 & & & \\
\hline & 3 & 2.03 & 30.50 & 67.33 & 0.62 & & & \\
\hline & 4 & 2.30 & 34.50 & 83.13 & 0.52 & & & \\
\hline & 5 & 2.23 & 33.40 & 78.58 & 0.55 & & & \\
\hline \multirow{5}{*}{$\begin{array}{c}\text { Sense of } \\
\text { Responsibility }\end{array}$} & 1 & 2.44 & 46.30 & 118.33 & 0.55 & 0.46 & 0.77 & Not significant \\
\hline & 2 & 2.37 & 45.00 & 114.90 & 0.68 & & & \\
\hline & 3 & 2.33 & 44.30 & 107.97 & 0.51 & & & \\
\hline & 4 & 2.57 & 48.80 & 129.78 & 0.50 & & & \\
\hline & 5 & 2.47 & 47.00 & 125.44 & 0.71 & & & \\
\hline \multirow{5}{*}{$\begin{array}{l}\text { Respect for } \\
\text { Others }\end{array}$} & 1 & 2.57 & 36.00 & 97.08 & 0.59 & 0.42 & 0.79 & Not significant \\
\hline & 2 & 2.34 & 32.80 & 83.16 & 0.70 & & & \\
\hline & 3 & 2.40 & 33.60 & 86.90 & 0.69 & & & \\
\hline & 4 & 2.56 & 35.80 & 96.98 & 0.65 & & & \\
\hline & 5 & 2.61 & 36.60 & 103.58 & 0.78 & & & \\
\hline
\end{tabular}


Table 12. Significant Difference between Performing Groups' Self-Control, Sense of Responsibility, and Respect for Ohers in Terms of Age

\begin{tabular}{cccccccc}
\hline & & Sum of Squares & $\mathrm{df}$ & Mean Square & $\mathrm{F}$ & Sig. & Interpretation \\
\hline \multirow{2}{*}{ Self-Control } & Between Groups & .485 & 8 & .061 & .783 & .618 & Not Significant \\
\cline { 2 - 8 } & Within Groups & 6.657 & 86 & .077 & & & \\
\hline \multirow{2}{*}{ Sense of Responsibility } & Between Groups & 1.245 & 8 & .156 & 2.404 & .022 & Significant \\
\cline { 2 - 8 } & Within Groups & 5.568 & 86 & .065 & & & \\
\hline \multirow{2}{*}{ Respect for Others } & Between Groups & 1.455 & 8 & .182 & 2.897 & .007 & Significant \\
\cline { 2 - 7 } & Within Groups & 5.401 & 86 & .063 & & \\
\hline
\end{tabular}

\section{Discussion}

\subsection{Demographic Profile of the Performing Artists}

There are 95 participants within the performing arts groups; forty-three (43) of them are female and 52 are male. In terms of length of service, the number of years rendered by the performers ranges from one (1) year to five (5) years. Most of the performers have been serving the group for three (3) and four (4) years. The age of the performers ranges from 18 years old to 29 years old. Majority of the performers are aged 19, and the next big bulk are aged 20 years old followed by the eighteen-year-old members.

\subsection{Description of the HEI's Performing Artists' Self-control, Sense of Responsibility, and Respect for Others}

\subsubsection{In Terms of Gender}

All of the performers across performing groups, regardless of gender, possess a very high level of self-control. According to the NLP-Motivational [14], when a person is self-controlled, he or she possesses the ability to exert control over his or her feelings and reactions, and even conduct himself or herself calmly and sensibly in difficult situations or when he or she is excited and angry. Given the performing artists' level of self-control, they have the power to do the right thing and refrain from doing the wrong things in life. Also, they have the ability to command their own thoughts, actions, and language. They can control their thoughts, temper, fear, speech, and bad habits.

Male and female performers within performing groups are mostly responsible performers. According to Good Character.com [15], when one agrees to do something, he or she should do it and answer for his or her actions; one should take care of his or her own matters, be trustworthy, and refrain from putting things off. Having found the performers to be mostly responsible indicates that they do what they are supposed to do; they plan ahead; they are diligent; they do their best; they think before they act; they are accountable for their words, actions, and attitude, and they possess self-discipline.

Also, all performers, either male or female, possess the traits of respecting others; they were described to be mostly respectful. They treat others with respect; they follow the golden rule; they are tolerant and they accept individual differences; they consider the feelings of others; they deal peacefully with anger, insult, and disagreement. According to Good Character.com [15], treating people with respect makes the world a nicer place to live in, whether it is at home, at school, or out in the community. It is, in fact, quite easy - every individual must treat other people the way he or she likes to be treated; one should not insult people or make fun of them; one should listen to others when they speak, value other people's opinions, be considerate, and refrain from mocking or teasing people; rather, everyone must be sensitive to other people's feelings and avoid pressuring someone to do something he or she does not want to do.

In general, the performing artists, either male or female, possess high level of emotional intelligence. The performers are change agents - they can embrace change; they are self-aware - they are in touch with their real selves. The respondents are empathetic - they can tap into the empathetic side; they are not perfectionists - they understand why perfection just does not work all the time. They also have a sense of balance - they know how to maintain balance in all aspects of life; they are curious they start exploring and they keep on learning, and they are gracious - they are grateful for all the good things.

\subsubsection{In Terms of Years of Service}

Performers who have rendered one (1) to two (2) years of service possess a high level of self-control while those who have served for three (3) to five (5) years have mastered a very high level of self-control. This means that as the performers stay longer with the performing arts group, they are able to develop their level of self-control even more. Members of the performing arts group who have rendered five (5) years of service are completely responsible while those in their first year to fourth year of service in the performing arts group are mostly responsible. Performers who have stayed in the performing arts group for one (1) to four (4) years possess a mostly respectful character while those in their third year and beyond possess a completely respectful character. According to Successful Grownup [6], as individuals develop a sense of belongingness and spend higher number of years in the 
group, they get to enhance their state of emotional intelligence all the more. Furthermore, according to the University Interscholastic League [5], the character that a person possesses grows when he or she stays in a group that possesses a certain quality that shapes the way its members live their lives and affects the manner in which other people view them.

\subsubsection{In Terms of Age}

All of the performing artists in the HEI possess a high level of self-control and are mostly responsible and mostly respectful. The performer with the longest stay in the group possesses a very high level of self-control and is completely responsible. This simply implies that as the performers stay in the group for many years and get older, their emotional intelligence grows at the same time. According to the journal of teachers, acting positively because of being properly guided by the people around a person may result to positive output. Inflexibility shows that the performers respect themselves and they have self-control; whereas, gentleness displays their respect for others.

\subsection{Significant Difference between the Levels of Self-control, Sense of Responsibility, and Respect for Others of the Performing Artists in the HEI When Grouped According to Gender, Years of Service, and Age}

In terms of gender, the data indicate that there is no significant difference between female and male performers on their levels of self-control, sense of responsibility, and respect for others. Moreover, there is no significant difference between the performers' level of self-control, sense of responsibility, and respect for others in terms of years of service rendered in the performing arts group. While in terms of age, the data signify that there is a significant difference on the performers' sense of responsibility and respect for others, but no significant difference was established on the performers' level of self-control. The data only show that as the performers mature in the group, their attitude or behavior also changes. It means that the members of the group are motivated to become real performers and that performing becomes their passion as they mature in the group. According to Mcleod [4], an individual with positive attitude develops a positive self-image. To become a good individual, one must possess a positive self-image and social acceptance. Performing artists build a positive self-image and social acceptance as they grow in the performing arts group. In addition, according to Cassidy from the book of Lopez et.al [1], best action is the result of positive outlook in life and scientific knowledge. As they get older in the group, the members enhance their skills as performers and at the same time boost their positive attitude or behavior.

\section{Conclusions and Future Study}

Based on the foregoing findings, the following conclusions were made:1. Both male and female performers in the performing arts groups possess a very high level of self-control; 2. Both male and female performers in the performing arts groups exhibit a responsible behavior; 3 . The performers in the performing arts groups, regardless of gender, possess a mostly respectful to completely respectful attitude; 4. As performers stay longer in the performing arts group, their state of self-control as well as their sense of responsibility and respect for others, progresses positively; 5. As performers get older, they are able to cultivate a better state of self-control, sense of responsibility, and respect for others; 6 . Performers' behavior varies, but most of the time, they have one thing in common - a positive outlook in life; 7. Every individual possesses a divergent behavior. Even twins' sets of behavior differ from each other. In general, it can be said that the behavior of the performing artists in the higher education institutions is very good, and 8 . Performing artists in the HEI uphold the value of self-control, sense of responsibility, and respect for others.

Based on the obtained findings and conclusions in the study, the following recommendations are hereby offered for future research: 1 . The result of the study could be used as basis for program development for the performing artists in the higher education institution; 2. The intensification of every performer's emotional intelligence should be incorporated in the performing arts program; 3. Newly accepted members of the performing arts group should take an emotional intelligence inventory test to gauge how emotionally prepared they are as performers. This will be the basis in the selection of specific activities that need to be given to the performers in order to enhance their emotional intelligence; 4 . Every performing group in the performing arts cluster should conduct teambuilding activities, seminar-workshops on personality development, and regular performance evaluation of every member; 4. The character of a true Angelite, must continue to be instilled in every performer; 5 . A yearly evaluation of the emotional intelligence of the performers must be conducted, and 6. For future research directions, a comparative study on the emotional intelligence of members of different performing arts groups in Pampanga may be conducted.

\section{REFERENCES}

[1] L.F.P. Lopez et al. Physical Education, Health and Music. Philippines: Rex Book Store, 2000.

[2] O. J. Simpson. Inspirational Quotes for Athletes. Retrieved from: https://www.inspirational-quotes-short-funny-stuff.c om/inspirational-quotes-for-athletes.html, 2010. 
[3] B. Tracy. Searchquotes.com. Retrieved from:http://www.se archquotes.com/search/Respect_Self_Control_And_Respo nsibilityhole/2/, 2013.

[4] J. McLeod.Introduction to Counselling. McGraw-Hill Education, 2009.

[5] University Interscholastic League. C.A.R.E.: Sportsmanship and UIL Athletics. Austin: Texas, 2000.

[6] The Successful Grownup. 20 Characteristics of Emotionally Healthy People. Retrieved from https://www.thesuccessful grownup.com/categories/self-awareness/item/20-characteri stics-of-emotionally-healthy-people\#.XN63t6QRXIU, 2014.

[7] Realities Watch. 10 Traits of a Person with High Emotional Intelligence. Retrieved from https://realitieswatch.com/10-t raits-person-high-emotional-intelligence/, 2016.

[8] J. Rampton. 10 Qualities of People with High Emotional Intelligence. Retrieved from https://www.inc.com/john-ra mpton/10-qualities-of-people-with-high-emotional-intellig ence.html, 2016.

[9] A. Gurian. About Discipline - Helping Child Develop Self-Control. Retrieved from NYU Child Study Center http://www.aboutourkids.org/articles/about_discipline hel ping_children_develop_selfcontrol, 2012.

[10] D. L. Dell. An Attitude Scale. Illinois State University, Normal, 1965.

[11] E.G. Adanza. Research Methods: Principles and Applications. Manila: Rex Bookstore, 1995.

[12] P.W. Airasian. Educational Research. Pearson Education, 2008.

[13] W. M. Vargas. Likert-type scale response anchors. Clemson International Institute for Tourism \& Research Development, Department of Parks, Recreation and Tourism Management. Clemson University. Retrieved from http://www.marquette.edu/dsa/assessment/documents/Sam ple-Likert-Scales.pdf, 2006.

[14] NLP-Motivational. NLP and Motivation (Helping you gain knowledge and understanding of your character). Retrieved from www.mymotivational-nlp.com, 2015.

[15] Good Character.com. Character Education Lesson. Retrieved from www.goodcharacter.com (NA). 